\title{
Promoção da saúde na metrópole com foco na intersetorialidade e sustentabilidade.
}

\section{Promoción de la salud en metropolis con el foco en la sostenibilidad y intersectorialidad.}

\section{Health promotion in metropolis with focus on sustainability and intersectoral action.}

\author{
Rosilda MENDES ${ }^{1}$ \\ Daniele Pompei SACARDO ${ }^{2}$ \\ Grace NORONHA ${ }^{3}$ \\ Helio NEVES ${ }^{4}$
}

Yamma Mayura Duarte ALVES ${ }^{5}$

\begin{abstract}
RESUMO: A complexidade do campo da promoção da saúde tem desafiado pesquisadores e profissionais a desenvolver métodos de avaliação para produzir uma base de evidências sobre a efetividade das políticas e ações empreendidas. Este artigo aborda da temática da produção da evidências da efetividade da promoção da saúde por meio da avaliação do "Programa Ambientes Verdes e Saudáveis - PAVS" implantado como uma política pública municipal em São Paulo/Brasil desde o ano 2009, tomando como dimensões analíticas a sustentabilidade e a intersetorialidade. A abordagem metodológica empreendida foi qualitativa assegurando ampla interação entre os gestores envolvidos no Programa e os pesquisadores. Foram realizadas entrevistas com os atores-chave selecionados a partir da posição gestora que ocupavam no Programa até o ano de 2011. Do ponto de vista analítico, foram observados aspectos que podem auxiliar no entendimento presente e nas perspectivas futuras das iniciativas de promoção da saúde. É significativo o entendimento entre os sujeitos do PAVS de que a sustentabilidade depende da criação de uma visão comum e de um modelo de análise também compartilhado. Essa investigação apontou que o fato de existirem parcerias, trabalho intersetorial, redes sociais, alianças, têm trazido resultados bastante positivos para a manutenção do Programa. Todos essas dimensões explicitadas nos depoimentos daqueles que constroem o Programa nos desafiam a pensar a promoção da saúde sob a ótica do desenvolvimento e da condição humana. Nesse sentido, o PAVS é exemplar, e seus aprendizados podem ser capazes de indicar
\end{abstract}

\footnotetext{
1 Docente do Departamento de Politicas Publicas e Saúde Coletiva. Universidade Federal de São Paulo Campus Baixada Santista Brasil. Contato: rosilda.mendes3@gmail.com

2 Pós-doutoranda do Departamento de Saúde Coletiva . Faculdade de Ciências Médicas da Universidade Estadual de Campinas/SP.

3 Educadora em saúde pública. Secretaria Municipal de Saúde de Guarulhos/ SP

4 Médico da SMS/S . Secretaria Municipal de Saúde de São Paulo

5 Médica da SMS/SP. Secretaria Municipal de Saúde de São Paulo
}

ISSN 1982-8829

Tempus, actas de saúde colet, Brasília, 8(3), 125-143, set, 2014// 
caminhos para a construção de soluções viáveis aos complexos problemas vividos nas metrópoles.

Palavras-chave: Promoção da Saúde. Intersetorialidade. Sustentabilidade.

ABSTRACT: The complexity of the field of health promotion has challenged researchers and professionals to develop methods of assessment to produce a basis of evidence as to the effectiveness of the policies and actions undertaken. This article addresses the theme of the production of the "Green and Healthy Environments Program - GHEP" ("Programa Ambientes Verdes e Saudáveis - PAVS") which has been being implanted as a municipal public policy in São Paulo/Brazil since 2009 ,taking sustentability and intersectorial action as analytical dimensions. The methodological approach adopted was qualitative, ensuring broad interaction between the managers involved in the Program and the researchers. Interviews were held with the key actors selected on the basis of the management positions which they held in the Program up to 2011. From the analytical point of view, aspects were observed which may help in the present understanding of health promotion initiatives and their future prospects. The understanding achieved between the subjects of the GHEP that sustainability depends on the creation of a common vision and on an also shared model of analysis is significant.This investigation indicated that the fact that there exist partnerships and social networks has produced quite positive results for the maintenance of the Program. All these dimensions brought out in the testimonies of those who are constructing the Program challenge us to think of health promotion within the perspective of human development. In this sense, the GHEP is exemplary, and the lessons learned from it may point to ways in which viable solutions for the complex problems experienced in the metropolises may be constructed. Keywords: Health Promotion. Sustainability. Intersectorial action.

RESUMEN: La complejidad del campo de la promoción de la salud ha desafiado a los investigadores y profesionales para desarrollaren métodos de evaluación para producir una base de evidencia sobre la eficacia de las políticas.En este artículo se aborda el tema de la producción de evidencias de la efectividad de la promoción de la salud a través de la evaluación del "Programa Ambientes Verdes y Saludables - PAVS" desarrollado como una política pública municipal en São Paulo/Brasil desde 2009, teniendo como dimensiones de análisis la sostenibilidad y la intersectorialidad. El enfoque metodológico adoptado fue cualitativo con una amplia interacción entre los gestores que participaban del programa y los investigadores. Fueron realizadas entrevistas con actores-clave seleccionados a partir de la posición de gestión que ocupaban en el Programa en el año 2011. De una perspectiva analítica fueron observados aspectos que pueden apoyar la comprensión del momento presente y las perspectivas futuras de las iniciativas de promoción de la salud. Es significativo el entendimiento entre los sujetos del Programa que la sostenibilidad depende de la creación de una visión común entre los participantes y de un modelo de análisis también compartido. Esa pesquisa mostró que el hecho de que hay asociaciones y alianzas han traído resultados muy positivos en el mantenimiento del PAVS. Todas estas dimensiones presentes en los discursos de aquellos que construyen el programa desafían a pensar la promoción de la salud desde la perspectiva del desarrollo y de la condición humana. En este sentido el PAVS es ejemplar y sus aprendizajes pueden ser capaces de identificar maneras de construir soluciones viables a los complejos problemas vividos en las metrópolis. 
Palabras-clave: Promoción de la Salud. Intersectorialidad. Sostenibilidad.

\section{INTRODUÇÃO}

A complexidade do campo da promoção da saúde tem desafiado pesquisadores, gestores e profissionais a desenvolver métodos e instrumentos de avaliação de programas e políticas públicas capazes de evidenciar os avanços, as potencialidades, assim como os limites das práticas nos serviços de saúde, em especial na Atenção Básica. Além de questões metodológicas, os agentes sociais vêm discutindo há mais de uma década a necessidade de produzir uma base de evidências sobre a efetividade das políticas e ações de promoção da saúde (WHO 2001; PAHO 2002) envolvendo governos, universidades e organizações não-governamentais para enfrentar esses desafios.

Promover saúde, no seu sentido mais amplo, significa promover a vida, o que se traduz em um conjunto de princípios, valores, atitudes, procedimentos e tecnologias dirigidas a aumentar a capacidade de indivíduos, populações e instituições para fazer frente aos determinantes sociais, ambientais, econômicos e individuais e interferir na qualidade da vida (Cerqueira, 1997; Buss, 1998 e 2000; Mendes, 2000; Westphal, 2006).

Diversos autores têm argumentado que políticas de promoção da saúde vêm sendo acompanhadas por uma preocupação em relação à avaliação de sua sustentabilidade (Moisés, et al, 2004; Pluye et al, 2004a; Pluye et al, 2004b Swerissen \& Crisp, 2004; Nguyen et al , 2005; Baldwin, et al, 2005; Gallo \& Setti, 2012; Buss et al, 2012 ; Vermeer et al, 2013). Uma dimensão a ser considerada nessas avaliações busca compreender se as ações empreendidas consolidam-se de modo a produzir mudanças significativas nas condições de vida e saúde da população, ou seja, interroga em que medida as mudanças foram significativas, profundas no sentido de criar novas institucionalidades nas relações entre governos e comunidades, ou no sentido contrário corresponderia à superficialidade das transformações desejadas.

Outras dimensões compreendem a sustentabilidade das ações de promoção da saúde comoresultado de parcerias, de ações intersetoriais e formações de redes em diferentes níveis, especialmente no âmbito local, como um complexo sistema de relações que envolve sujeitos e instituições na busca de soluções mais amplas e duradouras. Em outras palavras, tais visões concordam que analisar a sustentabilidade das políticas, projetos, programas ou iniciativas de promoção da saúde constitui uma dimensão longitudinal das ações, o que significa problematizar e analisar a possibilidade de sobrevivência quando das transições dos governos que se sucedem periodicamente e de continuarem a obter e manter os recursos para o desenvolvimento das atividades e, ainda, em que medida essas iniciativas podem manter os seus efeitos por um longo período.

Este artigo aborda a temática da produção de evidências da efetividade da promoção da saúde por meio da avaliação do "Programa Ambientes Verdes e Saudáveis - PAVS" implantado como uma política pública municipal em São Paulo/Brasil desde o ano 2009, tomando como dimensões analíticas a sustentabilidade e a intersetorialidade. Essas dimensões foram escolhidas em função da ISSN 1982-8829

Tempus, actas de saúde colet, Brasília, 8(3), 125-143, set, 2014// 
natureza intersetorial do programa, que articulou os setores saúde e meio ambiente na concepção e cogestão do PAVS desde seu princípio enquanto um projeto, em 2007. Seu foco, inicialmente, centrou-se na capacitação de cerca de cinco mil agentes comunitários de saúde (ACS) em conteúdos relacionados à temática ambiental, seguida, no ano seguinte, de elaboração e implantação de projetos socioambientais na Atenção Básica/Estratégia Saúde da Família, envolvendo as comunidades locais em todas as regiões da cidade, consolidando-se como uma política pública no ano 2009. A dimensão da sustentabilidade nessa avaliação encontra lugar devido ao PAVS resistir às mudanças de governos municipais e à ampliação de seu escopo ao longo do tempo, de um projeto à consolidação enquanto uma política pública municipal.

Como todo e qualquer campo científico, além do conflito de interesse, pressões corporativas e outros fatores que influenciam a produção de conhecimento e a tomada de decisões, a promoção da saúde apresenta uma dificuldade adicional por referir-se à constituição de sujeitos e à produção de subjetividades. A produção de evidências em promoção da saúde vai além das questões biológicas e abarca concepções sobre a autonomia dos sujeitos e os modos de levar a vida individual e coletiva (Campos, 2000 e Onocko-Campos, 2001). Os fatores que interferem neste processo têm efeitos e resultados paradoxais e inesperados, porque interagem com sujeitos que os elaboram de maneiras singulares. Concordamos com Campos (2000, p. 100) ao reconhecer que os "tradicionais métodos estatísticos têm dificuldade de encontrar regularidades quando se avalia a eficácia de procedimentos que interferem na dinâmica existencial das pessoas". Como recurso ao enfrentamento desses desafios, a abordagem metodológica utilizada nessa avaliação foi qualitativa, com a inclusão e participação dos gestores municipais dos setores saúde e meio ambiente e com a criação de espaços reflexivos que permitissem a construção coletiva dos valores comuns que permeariam todo o processo avaliativo - do objeto ao modo de disseminação dos resultados.

Desencadear mudanças nas práticas cotidianas de uma política da promoção da saúde representada pelo PAVS motivou gestores e pesquisadores a realizar o processo avaliativo. Os gestores, nesse caso, não foram apenas fontes de informação para a pesquisa, mas tornaram-se cogestores do processo avaliativo, tendo como instância mediadora para essa mudança alguns dispositivos participativos da pesquisa. Tomamos o conceito de "dispositivo como um agenciamento concreto" de Foucault (1988), também utilizado por Furtado (2001) e Passos et al (2008), na medida em que a avaliação da sustentabilidade do PAVS permitiu a emergência de um conjunto heterogêneo de elementos que compõem o programa, assim como interrogar sobre seu funcionamento e sua dinâmica, implicando os envolvidos na proposição das mudanças almejadas.

\section{PERCURSO METODOLÓGICO}

A abordagem metodológica empreendida foi qualitativa assegurando ampla interação entre os gestores envolvidos no Programa e os pesquisadores. Inicialmente foi realizado um levantamento bibliográfico que identificou experiências de promoção da saúde com enfoque na sustentabilidade. A partir do referencial bibliográfico levantado foi possível constituir as primeiras categorias 
analíticas que nortearam todo o processo investigativo bem como a elaboração dos instrumentos de coleta de dados. Para isso, foram realizadas entrevistas em profundidade com os atores-chave selecionados a partir da posição gestora que ocupavam no Programa até dezembro do ano de 2011.

Embora o PAVS seja um Programa desenvolvido em toda cidade de São Paulo, para essa pesquisa delineou-se o universo da região Sul uma vez que esta região apresentava maior número de projetos e instituições parceiras do Programa de Saúde da Família, responsáveis pela condução do Programa. Desse modo, foram realizadas vinte e três entrevistas: uma Coordenadora Regional Sul, duas Gestoras Regionais, seis Interlocutores das instituições parceiras no PAVS e quatorze Gestores Locais que atuavam nas cinco instituições parceiras em atividade durante o processo de pesquisa sendo quatro da Associação Saúde da Família, três da Associação Congregação Santa Catarina, dois da Associação Comunitária Monte Azul, dois do Instituto Israelita de Responsabilidade Social Albert Einstein, dois da UNASP- Universidade Adventista de São Paulo, e um do CEJAM - Centro de Estudos Dr. João Amorim.

Para a análise dos dados, inicialmente foram transcritas todas as entrevistas e realizada a leitura e releitura exaustiva do material coletado. Tomando como base o referencial teórico e pressupostos que orientaram o estudo, foram estabelecidas categorias empíricas confrontando-as com as categorias analíticas. A partir daí foi construído um quadro de análise que destacou as posições muito ou pouco valorizadas nas falas, trechos mais significativos dos discursos e as impressões e análises iniciais que serviram de base para a análise final. Os resultados da investigação foram agrupados a partir de categorias que destacam fatores que criam oportunidades e barreiras frente à capacidade de enfrentar o futuro e dar suporte à sustentabilidade do Programa intersetorial na metrópole de São Paulo: a) organização e processo de trabalho e b) intersetorialidade, parcerias e redes sociais

Os dados produzidos na etapa anterior foram discutidos em três "Oficinas de Análise" buscando aproximar-se da realidade e interpretá-la, atribuindo-lhe significados e sentidos. Essas oficinas foram essencialmente baseadas em processo participativo, envolvendo dois coordenadores do PAVS da Secretaria Municipal de Saúde e um pesquisador da Secretaria Municipal do Verde e Meio Ambiente. Os resultados do processo investigativo serão apresentados a seguir.

As entrevistas seguiram as Normas do Comitê de Ética da Faculdade de Saúde Pública da Universidade de São Paulo e da Secretaria Municipal de Saúde de São Paulo.

\section{RESULTADOS E DISCUSSÃO}

\section{a) Organização e processo de trabalho}

A forma como o PAVS é organizado e gerido em todos os níveis do sistema de saúde é um dos pontos cruciais que tem relação com a sua sustentabilidade, de acordo com os entrevistados. Analisar o processo de trabalho de um programa como o PAVS significa analisar também sua gestão, 
olhar para suas múltiplas dimensões de forma a poder não apenas lançar luz no funcionamento da instância responsável por operacionalizar sua implantação, mas também visualizar a dinâmica das atividades do programa propriamente ditas, bem como as funções e papéis desempenhados por cada um dos sujeitos envolvidos.

Inicialmente, cabem algumas considerações acerca do lócus onde o PAVS é desenvolvido, ou seja, a Unidade Básica de Saúde. Embora especificamente as ações do Programa não estejam diretamente relacionadas ao processo de "cuidado" e à atenção de pessoas doentes, o modo de agir dos ACS se aproxima dessa realidade, frequentemente permeada por dor e sofrimento. Assim, ao executar seu trabalho, os profissionais de saúde, entre eles os ACS, obedecem a uma certa lógica do seu processo de trabalho cotidiano numa UBS, há para cada profissional tarefas e atividades particulares, há lugares específicos onde certos produtos são realizados e resultados são alcançados. Há uma inter-relação, no trabalho, entre todos os profissionais como o funcionamento de uma "rede de conversas e de relacionamentos", mediada pelo trabalho.

Nesse contexto de produção de saúde, o PAVS se insere como um proposta que escapa da lógica do cuidado e propõe uma prática diferenciada em relação ao modo de agir do ACS e, consequentemente, de toda a equipe da Estratégia de Saúde da Família. Isso não ocorre, entretanto, isento de conflitos e dificuldades para todos os atores envolvidos. A inclusão das atividades relacionadas ao PAVS na rotina do ACS é uma das questões centrais para a compreensão dos avanços e dos desafios que o programa procura enfrentar. Esse processo passou por fases ou etapas que informam tanto sobre a organização do trabalho no PAVS atualmente quanto sobre as dificuldades e formas de enfrentamento encontrado pelos sujeitos envolvidos em sua implementação.

Uma das principais questões para a compreensão do processo de trabalho diz respeito à clareza dos papéis ou das funções de cada profissional envolvido com o Programa. As entrevistas indicam uma divisão de papéis entre o interlocutor, os gestores locais e os Agentes de Promoção Ambiental (APA), sendo que há uma queixa de sobrecarga nas funções dos gestores locais.

Como parte do processo de trabalho encontra-se a designação de pessoas, geralmente os ACS, responsáveis por atrair participantes para as reuniões do PAVS e cooperar no desenvolvimento das atividades relacionadas aos projetos.

$O$ ator principal do PAVS é o ACS, porque se a gente não tiver o ACS trabalhando junto não tem como você entrar na comunidade, não tem como você conseguir as pessoas da comunidade para vir, sem o agente, não existe o PAVS. (GLU1)

Essa é uma dimensão importante a se considerar - a valorização e satisfação dos ACS com a sua prática, mais dotada de sentido. De alguma forma, os entrevistados indicam que o trabalho do agente comunitário qualifica-se no PAVS, passa a integrar mais efetivamente o trabalho em equipe, a prática deixa de ser restrita apenas ao atendimento individual, fragmentado, e eles passam se 
envolver efetivamente com a prática da promoção da saúde.

Os depoimentos dos gestores historicizam a implantação do PAVS na cidade de São Paulo, e revelam o quanto foi questionado por não ser institucionalizado como um Programa desde o seu início, e por não ter tido um "lugar" bem definido na política pública municipal.

Outra temática muito importante para o desenvolvimento e consolidação do programa foi a contratação dos Agentes de Promoção Ambiental (APA), que tornou o programa mais próximo da UBS e proporcionou maior capilaridade às ações, descentralizando cada vez mais. Foi um facilitador essa divisão, os APA eles é que representam a gente lá no território, então eles vão atrás, vão buscar parcerias, vão conversar, divulgam todos os nossos projetos nas reuniões de equipe, então vai, ele é um facilitador do gestor local, com os ACS e toda a dinâmica da unidade com a comunidade. (GLE2)

O desenvolvimento do programa depende em grande parte do envolvimento e comprometimento dos gerentes das Unidades, da equipe e dos ACS e APA. Percebe-se que o APA, para se envolver e conseguir trabalhar precisa de um processo de qualificação, de educação permanente que possibilite a compreensão dos processos em que ele é corresponsável e ajudando-o tanto para encontrar caminhos e estratégias para desenvolver seu trabalho quanto na produção de sentidos para sua prática.

O papel do gestor local é fundamental no processo de trabalho do PAVS, pois é ele que articula os projetos e viabiliza a sua concretização, busca parceiros e inclui o APA nas atividades previstas. O diálogo e a interação com os sujeitos envolvidos num projeto é um dos principais ingredientes da ação do gestor local, que se propõe a tecer uma rede de parceiros e instituições em torno de um objetivo comum, que é o que concretiza num projeto.

Um item principal para um gestor, seja ele regional ou local é de fazer uma boa articulação, ser articulador, porque você vai ter que conversar desde um catador, uma pessoa humilde financeiramente, que não tem grau de instrução nenhuma até o prefeito da cidade, governador ou deputado estadual. (GLU1)

Entretanto, a questão dos limites de financiamento dos projetos atravessa o programa e está fortemente presente nos relatos dos entrevistados. O recurso financeiro no PAVS pega muito, porque você tem muitas ideias e você não tem muito recurso para você realmente "ah, preciso fazer uma coleta coletiva, mas preciso de tambor x", ai e as próprias empresas que poderiam ser parceiras ainda tem essa dificuldade, de estabelecer essa parceria. (Coord.E)

Em relação à coordenação do programa, alguns consideram que a instituição parceira contratante nem sempre está em consonância com os coordenadores do Programa que trabalham no setor público, na SMS e isso gera desconfortos e conflitos que precisam ser considerados. Para mim sempre foi muito complicado, ter uma coordenação do programa e outra coordenação do parceiro, acho que 
os agentes, os APA, eles também sofrem isso porque tem, por exemplo, a minha coordenação e a coordenação do gerente da unidade, acho que isso realmente está melhor, porque conforme as pessoas vão se integrando e os discursos vão ficando mais harmônicos, mais unificados. ... (GLE2)

Parece importante trazer para a discussão sobre a sustentabilidade do PAVS questão do "trabalho em equipe", tendo em vista que isso foi mencionado por diversos entrevistados como uma prática presente no programa e valorizado enquanto norteador das ações e projetos desenvolvidos nos territórios. A organização do trabalho em equipe é uma temática que tem sido aprimorada ao longo do tempo do programa. Se, por um lado, a chegada do APA significou uma "ponte" entre o gestor local e a UBS, por outro, isso trouxe um desafio de capacitá-los para desempenhar o papel de multiplicador ou de articulador no âmbito local.

O modo de conduzir e organizar o processo de trabalho também tem passado por mudanças importantes ao longo do tempo. Inicialmente, a demanda ou indicação de temáticas a serem trabalhadas ocorria de maneira vertical, ou seja, a coordenação das parceiras da Estratégia de Saúde da Família definia os temas a serem trabalhados, ao passo que presentemente as definições são feitas em conjunto com outros sujeitos, considerando as necessidades dos territórios.

Alguns autores defendem que a ideia do trabalho em equipe, muitas vezes, aparece revestida de um ideal de solução para todas as dificuldades no processo de trabalho em saúde, como possibilidade de totalização dos trabalhos fragmentados, equipes-salvação e equipes-cooperação (Brasil, 2009). Em geral, a idealização do trabalho em equipe como uma "família" na qual os sentimentos de amizade prevalecem escamoteia uma realidade mais complexa e que inclui aspectos difíceis de serem abordados, como as relações corporativistas e as disputas de poder presentes nas relações humanas e, consequentemente, nas relações de trabalho. Abordar o tema das "relações" significa considerar o campo afetivo da produção de subjetividade. Portanto, a busca e o encontro de sentidos e significados para o pensar e agir do trabalhador da saúde, que no caso especifico do PAVS, se concretiza nos profissionais diretamente envolvidos com a implantação do programa.

As equipes que atuam na saúde estão imersas em relações de poder, de afeto, de trabalho, de gênero, relações sociais, históricas, culturais que produzem pensamentos, sentimentos, modos de agir e desejos. As relações de poder no interior das equipes, por exemplo, são históricas e se reproduzem no processo de trabalho. As histórias das profissões, em geral, são de conflito, como a Medicina e a Enfermagem, pois seus objetos são entrelaçados. Nas equipes, essa luta se atualiza e nela também estão as relações de gênero - homem, mulher. As relações afetivas: prestígio e subordinação. As relações de classe social e as decorrentes da diversidade cultural.

A equipe se constitui, por conseguinte, em um tecido de relações entre diferentes trabalhadores, permeadas pelas relações entre os trabalhadores e os usuários. São pessoas com diferentes formações, saberes, práticas, histórias, que se encontram e desencontram para produzir um trabalho: cuidar de pessoas com necessidades de saúde, gerenciar serviços e sistemas de saúde, formular 
projetos de promoção da saúde e de felicidade. Mais razoável seria considerar a equipe como uma possibilidade de construção/desconstrução/reconstrução permanente. Nela há movimentos, momentos de maior potência de trabalho, sinergia, organização, momentos de maior desarticulação, desânimo, resistência, momentos de criação e de invenção.

Somente a colocação dos trabalhadores juntos num mesmo ambiente não se configura suficiente para construção da equipe. Os trabalhadores precisam ser agenciados para o "modo-equipe" de trabalhar (Brasil, 2009). Ou seja, como um modo que os trabalhadores se rearranjam para atender uma pessoa/família/grupo ou para desenvolver um projeto coletivo, como no caso do PAVS.

Se o PAVS cresceu e tem fomentado muitas iniciativas articuladoras do campo da saúde e do meio ambiente, ainda podem ser observados vários entraves na sua consecução. Um deles, muito referido é o fato de que o setor da saúde ao trabalhar fundamentalmente com as metas quantitativas definidas para o Sistema de Atenção Básica, não incluiu ainda os resultados do Programa em seus indicadores: A saúde trabalha muito com metas, ela trabalha muito com indicador, a saúde ela tem sempre um objetivo, ela tem sempre aquele número, e é muito quantitativo, e não qualitativo... Então, eu acho que talvez o caminho que segue o PAVS é essa linha, da gente estabelecer um pouco metas, de talvez o PAVS entrar como um dos indicadores, de acompanhamento mesmo da Estratégia de Saúde da Família (IMA)

Outra questão relacionada ao processo de trabalho diz respeito à inserção do PAVS na Atenção Básica e a influência da política nacional no âmbito local, ou seja, a dificuldade de ser conhecido e reconhecido entre seus pares passa também pelo fato de ser um programa que não tem expressão no nível federal, o que se reproduz no âmbito municipal. Acho que às vezes também a gente tem essa coisa de Ministério, de que o PAVS não está no Ministério, a gente tem essa mania de ser dado, e dado, de um departamento e a gente fica com tanto dado na cabeça que o PAVS não tem lugar nenhum, talvez a gente acabe nem dando tanta importância.(CoordE)

Há de se destacar um aspecto positivo bastante mencionado pelos gestores locais que pode potencializar a sustentabilidade do PAVS - a criação de fóruns de debates entre as regiões da cidade de São Paulo. Esses fóruns são espaços de debate de eixos temáticos e troca de experiências.

Parece haver consenso entre os entrevistados de que a forma de registro, monitoramento e avaliação dos resultados do Programa é muito importante para a sustentabilidade do programa, ainda que haja muito a fazer nesse campo. Os relatórios mensais e bimensais registram desde dados qualitativos até os de natureza quantitativa. Há um esforço também de se definir metas e indicadores para acompanhar os resultados das ações no nível local. Os depoimentos revelam mais uma vez a importância de instrumentos de medida, mas aponta também como eles são distintos daqueles que a Secretaria de Saúde utiliza em seus sistemas. Coloca-se também a importância de lidar com indicadores ambientais que são mais complexos e nem sempre de fácil mensuração, bem como de criar novos instrumentos para avaliar a qualidade das ações empreendidas. O depoimento 
abaixo é exemplar nesse sentido:

... a gente tem os instrumentais oficiais que são gerados pelas próprias regionais as gestoras regionais do Programa, que elas elaboraram, então tem relatório mensal, as fichas de cadastro de estrutura dos projetos, fora isso, nós sendo parceiro temos algumas fichas, algumas coisas elaboradas para pegar os resultados. Para a sustentabilidade do programa é um pouco frágil porque como que você pensa numa sustentabilidade de um programa quando a Saúde são dados... Então assim, a gente tem ai dois pesos e duas medidas... (GMA1)

Para a sustentabilidade do programa, segundo os entrevistados, é fundamental que, de fato, a população "tome conta", se aproprie dos projetos que são desenvolvidos e isso nem sempre acontece na prática, portanto, se configura também como um desafio.

...sustentabilidade quando você está criando alguma coisa, quando ele começa a se reproduzir, a população toma conta dele, a comunidade toma aquilo para si e você sai de campo porque você implanta e dá estrutura para que aquilo continue [...] eu não vejo, me desculpe, mas eu não vejo, tanto que, por exemplo, um gestor que sai da Unidade o projeto acaba, um projeto tem que ser maior do que uma pessoa. (G1ASF).

\section{b) Intersetorialidade, parcerias e redes}

A intersetorialidade já adquiriu relevância como um pilar básico no enfrentamento da determinação social do processo saúde-doença, e o PAVS é um projeto exemplar nessa direção. A intersetorialidade é um dos eixos do Programa desde a sua criação, em 2006, e busca articular dois campos, saúde e meio ambiente por meio de duas secretarias municipais estratégicas na cidade de São Paulo, a Secretaria do Verde e Meio Ambiente e a Secretaria Municipal de Saúde. Essas instituições se uniram, naquele período, em torno de uma proposta alternativa de utilização dos recursos orçamentários de um Programa vinculado à SVMA voltado para a execução de ações de educação ambiental no âmbito do PSF. Outras secretarias de governos, como a Secretaria Municipal de Assistência e Desenvolvimento Social e a Secretaria da Educação também têm participado em alguns momentos de ações mais pontuais realizadas ao longo desses anos. Também as subprefeituras são tidas como importantes apoiadoras da ação no nível local.

Conceitualmente a intersetorialidade enfatiza ora muito mais o papel de sujeitos e não de organizações, outras vezes, enfatiza as instituições, ainda que privilegie um enfoque em territórios específicos (Junqueira, 2000). Há, ainda, entendimentos que apontam claro posicionamento político e explicitam a intenção da intersetorialidade como meio e não como um fim em si mesma na articulação de saberes e nas experiências no planejamento (Junqueira \& Inojosa, 1997). Outros autores ressaltam a potência da gestão intersetorial ao priorizar a abordagem dos territórios e ao enfatizar um trajeto metodológico que realiza a leitura crítica do território, a inclusão da pluralidade dos atores e o enfrentamento das práticas e dos saberes fragmentados. A gestão 
intersetorial apresentaria, nessa visão, as oportunidades para consolidar sujeitos políticos locais e contribuir para o desenvolvimento de uma cultura política democrática, mediante a implementação de políticas públicas comprometidas com o desenvolvimento humano sustentável (Fernandez \& Mendes, 2007).

Essas concepções trazem úteis elementos no sentido de articular sujeitos e processos organizacionais, superar fragmentações, tomada do território como referência das ações, sinergia para dar potência no enfrentamento de problemas complexos e produzir melhor saúde, efetivar políticas públicas, enfrentar exclusão social e promover a equidade.

O PAVS desde sua implantação incentivou e deu importância às relações em parcerias e aquelas advindas das redes locais no modo de pensar e realizar os projetos no nível local. Um pressuposto que vem sendo referendado por alguns estudiosos é o de que as parceiras e as redes asseguram maior sustentabilidade e legitimidade política à ação e introduzem a dimensão da cooperação e da participação conjunta. Possibilitam, ainda, o encontro de diferentes sujeitos em diferentes estágios de organização, a ampliação de possibilidades de cada organização, acrescentando conhecimentos, redefinindo focos, bem como o aproveitamento do potencial de cada organização participante. Trabalhar juntos, no entanto, é o grande desafio, já que o trabalho em parcerias e em redes sugere uma arquitetura de complementaridade na ação, que implica em uma nova cultura no fazer social público, especialmente no que diz respeito a socializar o poder, negociar, trabalhar com autonomias, flexibilizar, compatibilizar tempos heterogêneos e múltiplos dos sujeitos e processos de ação. (Carvalho, 2003)

Um componente importante da intersetorialidade apontada pelos entrevistados é a relação horizontal entre os parceiros do programa, ou seja, há a necessidade de todos perceberemse "ganhando", numa perspectiva de solidariedade e apoio mútuo: O PAVS veio para articular diferentes setores, para pactuar, é uma relação entre diferentes atores que buscam identificar um objetivo comum. (GR1)

A intersetorialidade é algo a ser construído no cotidiano, não há uma receita ou percurso único que leve a sua realização, mas apresenta um sentido de busca, de devir, de investimento, de espaços para diálogo: Então, quando a gente fala de articulação ...não dá para ter uma diretriz única no município ..., a gente está construindo isso essa intersetorialidade, a gente não tem como dizer " a fórmula é essa.... (GR1)

Uma importante consideração sobre a intersetorialidade seria o reconhecimento que o "outro" da relação intersetorial sempre tem o que dizer, ou seja, em uma determinada situação de projetos, por exemplo, os demais setores precisam se sentir parte do processo de construção. Assim, os processos tendem a ser mais bem sucedidos quando são construídos em conjunto. Para alguns dos gestores locais, a intersetorialidade ocorre naturalmente, nas articulações com os técnicos de outros setores, e podem ser consideradas políticas públicas intersetoriais geradas a partir do território. 
Da forma que se estruturou nos últimos anos o Programa cresceu com um protagonismo da área de saúde, muito embora sejam reconhecidos os efeitos positivos das tentativas de articulação intersetorial que sempre permeou seus objetivos. De acordo com os entrevistados faz-se necessário ainda envolver outras instâncias, além das duas Secretarias Municipais que sempre estiveram à frente da proposta.

O fato de ser uma política que reforça a intersetorialidade é ressaltado pelos entrevistados como potencializadora de sustentabilidade. Mas algumas vezes, quando há menção ao que caberia a cada uma das instituições, a Secretaria da Saúde, por exemplo, foi citada como sendo responsável principalmente pela regulação dos recursos. A ela tocaria o papel de definir os recursos que serão repassados para as instituições parceiras do Programa de Saúde da Família. Segundo o relato dos entrevistados o programa conta muito com apoio da Secretaria do Verde e Meio Ambiente para o desenvolvimento dos projetos, mas é interessante que isso aparece mais com um "apoio", uma ajuda e não como de fato um papel a ser cumprido por essa Secretaria.

Na perspectiva de alguns entrevistados a intersetorialidade ocorre na prática com o apoio e a cooperação entre as secretarias no processo de implantação de projetos e ações no território. Aqui é valorizado o papel das instâncias descentralizadas da Secretaria do Verde e Meio Ambiente. Mas é reconhecido, por outro lado, a insuficiência dessa forma de atuar. Não basta a boa vontade, diz a gestora: ...falta um pouco mais de políticas públicas mais fortes assim, para gente conseguir engatar mesmo, aquela coisa mesmo da exigência e aí o negócio vai decolar mesmo.(GSC2)

Em decorrência dessas desarticulações as ações são limitadas e muitas vezes pontuais, não se transformam as políticas e nem são geradoras de mudanças: ... você consegue fazer palestra de saúde ambiental, você consegue vacinar, você consegue trazer esse catador para a unidade, já é um passo importante, mas você não consegue porque não tem uma política de resíduos, cadastro dos catadores, do catador estar dentro de uma política pública na subprefeitura ou no município... (ISC)

Esses depoimentos explicitam que não tem sido tarefa simples para os sujeitos envolvidos concretizarem as ações de modo intersetorial ou intersecretarial e as justificativas para isso são diversas, como a falta de espaços para diálogo e planejamento, dificuldade para mobilizar outros setores para a causa ou temática, divisão de tarefas e responsabilidades, predomínio da agenda sanitária sobre as demais agendas, até a dificuldade de comunicar e explicitar os resultados do processo que o programa tem alcançado.

O significado do PAVS no âmbito da intersetorialidade e das relações entre setores e níveis de governo diz respeito a sua função mediadora, ou seja, cabe à equipe do programa desenvolver mecanismos e estratégicas de mediação de conflitos que viabilizem o diálogo e a comunicação de grupos para alcançar um objetivo. Isso tanto faz parte do processo de trabalho quanto compõe uma das funções da construção das práticas intersetoriais. 
Outra questão abordada nas entrevistas foi a relação conflituosa entre a "autoria" dos projetos, ou seja, parece que há uma cultura das secretarias de se tornarem exclusivamente as detentoras da autoria, mas o PAVS requer uma postura diferente, que os parceiros dos projetos o considerem uma coautoria, algo compartilhado.

A Portaria recém-promulgada pela Atenção Básica tem sido considerada um importante instrumento de ampliação das possibilidades de parcerias entre as secretarias, mas por ainda ser recente não foi possível verificar os resultados alcançados.

No relato dos entrevistados há uma demanda de que essa intersetorialidade e mesmo o apoio das secretarias se dê de forma mais concreta na formação de parcerias, como relata uma gestora local para a resolução de um problema em uma das ações desenvolvidas:... no município a gente viu mais de três toneladas de pilhas foram recolhidas por meio do PAVS, fazendo os coletores e implantando, três toneladas, agora você imagine como é que a gente está destinando isso dai? (G2ASF)

Como as relações intersetoriais incluem diferentes sujeitos e perspectivas, expectativas e interesses, os gestores defendem que há necessidade de desenvolver habilidades de mediação de conflitos, como explicita o depoimento: O PAVS é um programa de mediação de conflitos do território entre os setores, porque quando ele trabalha a intersetorialidade, ele já está partindo de uma realidade que a intersetorialidade e integração das ações entre os interessados. (GR1)

Tais conflitos tendem a se agravar a depender do grau de comprometimento e envolvimento dos setores, assim como da "maturidade" das parceiras da ESF.

Algumas experiências intersetoriais já têm uma história, você vai encontrar projetos bem bacanas até de ações de implantação de tratamento de água cinza numa unidade básica de saúde, mas também você encontra parceira que dificulta essa relação, que não tem tanto traquejo e aí temos que estar mais próximos. Então é para você saber que ele tem muitas diferenças de implantação. (GR2)

Embora se reconheça que a intersetorialidade requer uma abordagem entre setores, é preciso considerar que são as pessoas quem constroem as relações intersetoriais. Isso depende basicamente da abertura para que um setor possa se incluir no processo de implantação do PAVS.

O PAVS desde sua implantação incentivou e deu importância às relações em parcerias e àquelas advindas das redes locais no modo de pensar e realizar os projetos no nível local. Um pressuposto que vem sendo referendado por alguns estudiosos é o de que as parceiras e as redes asseguram maior sustentabilidade e legitimidade política à ação e introduzem a dimensão da cooperação e da participação conjunta. Possibilitam, ainda, o encontro de diferentes sujeitos em diferentes estágios de organização, a ampliação de possibilidades de cada organização, acrescentando conhecimentos, 
redefinindo focos, bem como o aproveitamento do potencial de cada organização participante. Trabalhar juntos, no entanto, é o grande desafio já que o trabalho em parcerias e em redes sugere uma arquitetura de complementaridade na ação que implica em uma nova cultura no fazer social público, especialmente no que diz respeito a socializar o poder, negociar, trabalhar com autonomias, flexibilizar, compatibilizar tempos heterogêneos e múltiplos dos sujeitos e processos de ação. (Carvalho, 2003)

Esses aspectos puderam ser evidenciados nessa pesquisa. Há uma constatação de que a formação de parcerias e redes sociais é fundamental para o andamento dos projetos que são elaborados no Programa. Desta forma, são realizadas parcerias com diversas entidades, para uma série de fins. Ao serem indagados sobre quem seriam os principais parceiros do Programa os entrevistados mencionam sujeitos tanto diretamente relacionados ao PAVS, como, por exemplo, os gestores locais, os gestores regionais, gerentes das UBS e ACS, as coordenadoras do nível central, como as instituições ou equipamentos sociais pertencentes ao território de ação.

Para a sustentabilidade do programa tem que ter uma rede muito forte construída" (GASF2). Um aspecto muito positivo do programa é que ele vem para tecer uma rede integrada, de integração de vários setores, várias secretarias. (GR1)

A perspectiva de consolidar uma rede integrada no território ter sido uma busca constante ao longo dos anos do PAVS, esse é um dos seus objetivos que continua sendo perseguido. Para a realização dessas parcerias, inicialmente é necessário fazer um mapeamento do território, saber quais instituições e equipamentos sociais que estão presentes e tentar articular com lideranças comunitárias, escolas, instituições religiosas, CEU, NASF, outros profissionais da UBS (saúde bucal, farmácia). As parcerias, quando colocadas em prática, são um importante fator de sustentabilidade, porque passam a se apropriar do tema do programa e de aplicar isso no cotidiano, a própria comunidade passa a ter um cuidado maior do território quando ela participa ativamente das ações: ...eu vejo que para a sustentabilidade dos projetos, das ações no local esses articuladores, o primeiro passo é o próprio envolvimento deles, e aí quando ele percebe que ele amplia o olhar dele de atuação e ele vê como é importante construir junto ... (G2ASF)

A interlocução com outras parcerias além do poder público, como ONG, facilita a divulgação do programa e publiciza as ações em desenvolvimento, como aponta o relato: O Movimento Nossa São Paulo, é um movimento que ele traz bastante experiência de vários países e o PAVS está lá dentro também, então acho que até onde o PAVS chegou o movimento Mostra São Paulo foi uma mídia de divulgação das ações que foi a mais abrangente até agora assim, na minha visão. (GR1)

O setor da Educação aparece também como um importante parceiro na comunicação do programa, mas sua atuação ainda é muito pontual. Também merecem destaque as parcerias estabelecidas com as comunidades locais o que de certa forma qualifica e reconhece a incompletude e necessária complementaridade entre serviços e sujeitos sociais. A comunidade torna-se um elo fundamental 
para a sustentabilidade do programa e sua divulgação. Assim, a sustentabilidade desse Programa também requer um investimento maior na comunidade, nos vínculo e na produção de sentidos para as práticas desenvolvidas no âmbito comunitário. Assim, as ameaças políticas ou de outras naturezas, não serão determinantes na continuidade e permanência do programa.

É muito tranquilo, porque é com a população direta, a população se sente como corresponsável do meio ambiente e da sustentabilidade, então a partir do momento que você faça um projeto com a comunidade, ela tende a apoiar. (CRS)

... a gente precisa gerar com os recursos que consigamos no caminho, com apoios locais, da comunidade, do comércio pequeno, da rede, a rede nos salva a pátria.(G3ASF)

Nesse sentido, o estabelecimento de parcerias também ocorre para viabilizar os projetos no nível local, ou seja, para captar recursos a serem destinados à execução de projetos, como relata $o$ entrevistado:

A gente consegue é lógico que, um dos objetivos do PAVS é garantir a sustentabilidade das ações no território, então para isso a gente busca parcerias no território, por exemplo, então com alguma empresa que atua ali no território, com o açougue do Sr. Zé, com a Padaria do Sr. Manoel, com a Casa de Construção de alguém, e isso funciona em alguns estados. (GR2)

O sorveteiro daqui que tem na esquina de uma das unidades é um tremendo de um cara que apoia o que a gente faz, que ele está sempre ali, entendeu? Mas é o Sr. Zequinha da sorveteria, não é uma indústria. Depende da vontade da pessoa. (GSC1).

Também as igrejas têm sido espaços estratégicos para aglutinar as comunidades. A igreja sempre abre os espaços para gente estar fazendo as oficinas, ficam junto com a gente também nas oficinas, dão ideias, e esses espaços são articuladores da comunidade também, então eles são facilitadores nossos, então quando a gente divulga uma oficina na igreja, o padre divulga nas missas, então acaba fazendo essa articulação que é muito bacana.. ".(IMA). Mas isso tem gerado alguns problemas: “...porque tem gente que fala "ah é igreja evangélica eu não vou então?”, então a gente tem que ir para outro lugar, mas assim, são parceiros, acho que são portas, então tem ajudado bastante. (GMA1)

Reconhecer o parceiro, atuar em conjunto nem sempre tem sido uma tarefa fácil, especialmente tendo em vista a complexidade das questões ambientais que são identificadas no cotidiano, e que são parte de uma problemática mais ampla na cidade:" ... às vezes a unidade ou a gente, por exemplo, quer uma coleta de pilha que é uma coisa que a gente gostaria muito de ter em todas as unidades, é um exemplo concreto, e a gente não consegue por quê? É fácil pôr uma coletora e começar a coletar? É fácil, mas a gente tem a logística reversa? Para onde é que vai essa pilha?.... (ISC) 
A extensão do território e a diversidade de equipamentos de saúde, sujeitos envolvidos nos distintos programas e variedade de ações - assistência direta, vigilância, promoção à saúde, estabelecimentos de parcerias em diferentes níveis, gestão e administração de recursos -, foram considerados fatores que muitas vezes dificultam o acompanhamento mais próximo do PAVS pela Coordenadoria. No entanto, a trajetória, os parceiros e o desenvolvimento das ações nos territórios ampliam as possibilidades de sustentabilidade do programa.

Por fim, há de se considerar que alguns desafios ainda se colocam em relação às ações intersetoriais no Programa, como apoiar e ampliar as redes intersetoriais para fortalecimento das alianças promovidas pelos projetos locais, bem como reafirmar, sempre que possível e necessário, a potencialidade da intersetorialidade estabelecida e fomentada no nível local, especialmente aquelas ações que envolvem a comunidade e outros sujeitos sociais locais.

\section{CONSIDERAÇÕES FINAIS}

A questão da sustentabilidade e da intersetorialidade sempre fizeram parte das reflexões daqueles que atuam no campo da promoção da saúde, mas pouco temos analisado os mecanismos que as determinam e os formatos que vão se estabelecendo.

Ao tomar o PAVS como objeto de estudo e reflexão pudemos observar vários aspectos que podem contribuir para que as ações se mantenham e/ou criem desafios ao seu desenvolvimento. Do ponto de vista analítico, ambos devem ser observados como aspectos que podem auxiliar no entendimento presente e nas perspectivas futuras das iniciativas de promoção da saúde.

É significativo o entendimento entre os sujeitos do PAVS de que a sustentabilidade depende da criação de uma visão comum e de um modelo de análise também compartilhado. Essa investigação apontou que o fato de existirem parcerias, trabalho intersetorial, redes de apoio social, alianças, têm trazido resultados bastante positivos para a manutenção do Programa. Sinteticamente pudemos agrupar cinco diferentes dimensões em relação à sustentabilidade do PAVS: a) estabelecimento de ações locais efetivas no território: é isso que caminha à sustentabilidade e as ações efetivas que a gente consegue fazer no território; b) incorporação das ações do programa na rotina da Estratégia de Saúde da Família: a adesão das equipes de Estratégia de Saúde da Família ao PAVS também é uma evidência clara de que ele ali está sendo sustentável, c) capacidade de capilaridade na região: A gente tem projetos na escola, de alfabetização, de cultura de paz, de uma nova cidadania; d) construção de institucionalidade junto ao Programa na Estratégia de Saúde da Familia: [o programa] tem que ser considerado realmente como um programa, ele é chamado de programa, mas ninguém o respeita; e) garantia de recursos para as ações: ...ele precisa ter uma verba para dar suporte.

Acrescentam-se a elas dois outros aspectos que merecem especial destaque. O primeiro diz respeito à correlação positiva que se estabelece entre a sustentabilidade do PAVS e o interesse, ou motivação dos profissionais, que passam a acreditar e a perceber a importância do projeto para a instituição onde atuam. O PAVS, muitas vezes, tem mobilizado nos sujeitos envolvidos - 
ACS, APA, gestores locais, equipes de Saúde da Família, gerentes, gestores regionais, comunidade, representantes das instituições parceiras - potência suficiente para continuar agindo, para produzir novos projetos, novas iniciativas e de atribuir significados e novos sentidos à experiência vivida. O outro aspecto se traduz como um desejo, como uma visão de futuro bastante forte, de que os projetos poderiam ser mais eficazes quanto mais se investisse em um planejamento que incluísse uma avaliação permanente. Esta avaliação envolveria um monitoramento constante, a criação de indicadores e o retorno das informações para os sujeitos envolvidos nos projetos. Ter os indicadores significaria mostrar os múltiplos resultados do processo e também uma forma de ampliar a capacidade de replicação da experiência para outros contextos municipais. Essa questão perpassa desde a importância de se ampliar a comunicação, de ter o Programa na boca de todo mundo, de ser reconhecido por meio de suas ações e intenções, até na capacidade de se investir em outras localidades.

Todas essas dimensões explicitadas nos depoimentos daqueles que constroem o Programa nos desafiam a pensar a promoção da saúde sob a ótica do desenvolvimento e da condição humana. Nesse sentido, o PAVS é exemplar, e seus produtos e aprendizados podem, sem dúvida, ser capazes de indicar caminhos para a construção de soluções viáveis aos complexos problemas vividos em nossas metrópoles.

\section{REFERÊNCIAS BIBLIOGRÁFICAS}

Baldwin L, Abernethy P, Roberts L, Egan H. Forming, managing and sustaining alliances for health promotion. Health Promot J Austr. 2005; 16(2):138-43

Brasil. Ministério da Saúde. Secretaria de Vigilância em Saúde. Departamento de análise de situação em saúde. Coordenação de Doenças e Agravos não transmissíveis. Curso de Extensão para gestores e profissionais do SUS em promoção da saúde. Brasília: Ministério da Saúde, 2009.

Buss PM. (org) Promoção da saúde e a saúde pública: contribuição para o debate entre as escolas de saúde pública da América Latina. ENSP. Rio de Janeiro; 1998.

Buss PM. Promoção da saúde e qualidade de vida. Ciência e Saúde Coletiva. 2000; 5(1): 163177.

Buss PM, Gallo E, Magalhães DP, Setti AFF, Netto FAF, Buss DF. Governança em saúde e ambiente para o desenvolvimento sustentável. Ciênc. saúde coletiva [online]. 2012, 16(6):14791491

Campos GWS. Um método para análise e co-gestão de coletivos. São Paulo: Hucitec, 2000. 236p.

Carvalho MCB. A ação em rede na implementação de políticas e programas sociais públicos” 
Cerqueira MT. Promoción de la salud y educacón para la salud: retos y perspectivas. In: Arroyo HV, Cerqueira MT. La promoción de la salud y educación para la salud en América Latina: un análisis sectorial. Puerto Rico:Editorial de la Universidade de Puerto Rico/OPS; 1997. p. 7-47.

Fernandez JCA, Mendes R. Gestão local e políticas públicas para a qualidade de vida. In: Fernandez JCA, Mendes, R. (Org.). Promoção da Saúde e gestão local. São Paulo: HUCITEC; CEPEDOC Cidades Saudáveis, 2007.p. 41-60.

Foucault M. História da Sexualidade I: a vontade de saber. Rio de Janeiro: Edições Graal, 1988.

Franco TB, Merhy EE. O reconhecimento de uma produção subjetiva do cuidado. Disponível em: $\quad$ http://www.professores.uff.br/tuliofranco/textos/reconhecimento-producao-subjetivacuidado.pdf [acesso em 18 de maio de 2014].

Furtado JP. Um método construtivista para a avaliação em saúde. Ciência e Saúde Coletiva, 6 (1), 2001, PP. 165-82.

Gallo E, Setti AFF Abordagens ecossistêmica e comunicativa na implantação de agendas territorializadas de desenvolvimento sustentável e promoção da saúde. Ciênc. saúde coletiva. Junho 2012. 17(6): 1433-1446.

Junqueira LAP, Inojosa RM.. Desenvolvimento social e intersetorialidade: a cidade solidária. São Paulo: Fundap, 1997.

Junqueira LAP. Intersetorialidade, transetorialidade e redes sociais na saúde. Revista Brasileira de Administração Pública. Rio de Janeiro, vol 34.n.6, p. 35-45, 2000

Mendes R. Cidades saudáveis no Brasil e os processos participativos: os casos de Jundiaí e Maceió. São Paulo; 2000. [Tese de Doutorado - Faculdade de Saúde Pública da USP].

Moysés SJ, Moysés ST, Krempel MC. Avaliando o processo de construçäo de políticas públicas de promoçäo de saúde: a experiência de Curitiba / Assessing the building process of health promotion public policies: the experience of Curitiba. Ciênc. saúde coletiva;9 (3) :627-641, jul.set. 2004.

Nguyen MN, Gauvin L, Martineau I, Grignon R. Sustainability of the impact of a public health intervention: lessons learned from the laval walking clubs experience. Health Promot Pract.2005 Jan;6(1)44-52.

Onocko Campos R. A gestão: espaço de intervenção, análise e especificidades técnicas. In: 
Campos (org). Saúde Paideia. São Paulo: Hucitec, 2001. p.122-149.

[PAHO] Pan-American Health Organization Health promotion evaluation: recommendations for policymakers in the Americas. Washington DC. 2002.

Passos, E; Souza, T; Aquino, P; Barros, R. Processo coletivo de construção de instrumentos de avaliação: aspectos teóricos e metodológicos sobre dispositivos e indicadores profissionais. In: Pesquisa Avaliativa em Saúde Mental: Desenho participativo e efeitos de narratividade. São Paulo: Hucitec; 2008. p. 375 - 397.

Pluye P, Potvin L, Denis JL, Pelletier J. Program sustainability: focus on organizational routines. Health Promot Int.2004 Dec19(4): 489-500

Pluye P, Potvin L, Denis JL. Making public health programs last: conceptualizing sustainability. Evaluation and Program Planning, 2004b.

St Leger L Questioning sustainability in health promotion Health Promot Int.2005 Dec; 20(4):317-9.

Swerissen H, Crisp BR. The sustainability of health promotion interventions for different levels of social organization. Health Promot Int. 2004 Mar;19(1)123-30.

Vermeer AJ, van Assema P, Hesdahl B, Harting J, de Vries NK. Factors influencing perceived sustainability of Dutch community health programs. Health Promot Int. 2013 Sep 9. Health Promot. Int. first published online

Westphal MF. Promoção da saúde e prevenção de doenças. Campos GWS; Minayo MCS; Akerman M; Drumond Júnior M; Carvalho YM. Tratado de saúde coletiva. Rio de Janeiro, Hucitec; Fiocruz, 2006. p.635-667.

WHO Regional Office for Europe. Evaluation in Health Promotion: principles and perspectives. WHO-Europe. Copenhague. 2001.

Artigo apresentado em 11/03/14

Artigo aprovado em 21/07/14

Artigo publicado no sistema em 12/09/14 